\title{
Influence of the surface microstructure on the adhesion of a CVD-diamond coating on steel with a $\mathrm{CrN}$ interlayer
}

\author{
Markus Prieske, ${ }^{1, *}$, Richard Börner ${ }^{2}$ and Andreas Schubert $^{2}$ \\ ${ }^{1}$ BIAS - Bremer Institut für angewandte Strahltechnik GmbH, Klagenfurter Str. 5, 28359 Bremen, Germany \\ ${ }^{2}$ Chemnitz University of Technology, Reichenhainer Straße 70, 09126 Chemnitz, Germany
}

\begin{abstract}
forming tool coating. Most of the forming tools are made of steel, so that especially the coatability of steel by a polycrystalline diamond coating would rise the range of fields of application. The polycrystalline CVD-diamond coatings are deposited by a laser induced plasma CVD process, without a vacuum chamber. Various surface microstructures were investigated regarding their influence on the residual stresses to prevent a flaking of the coating: on the one hand, deterministic structures generated by ultrasonic vibration assisted milling (UVAM) and on the other hand, stochastic structures manufactured by blasting and polishing processes. For the UVAM, a surface prediction tool was used to design the surface microstructure beforehand. All steel substrates (material no. 1.2379) were coated in one batch by high-power impulse magnetron sputtering with a chromium nitride coating with a thickness of $2.4 \mu \mathrm{m}$. The specimens were analysed by laser microscopy, scanning electron microscopy, energy-dispersive X-ray spectroscopy and Raman spectroscopy. None of the microstructures investigated in this study was able to prevent delamination of the coating entirely. It could be shown that a roughness higher than $\mathrm{Sa} 0.1 \mu \mathrm{m}$ supports the interlocking between coating and surface as well as that sharp peaks inhibit a homogenous diamond coating deposition.
\end{abstract}

Keywords: Micro structure, Diamond coating, Ultrasonic vibration assisted milling

Nomenclature

\begin{tabular}{|ll|}
\hline AC1 & first temperature of phase transformation \\
Aus & Ultrasonic amplitude: peak-to-peak \\
$\mathbf{A R}$ & Aspect ratio of the microstructure (Aus / $\lambda$ ) \\
$\mathbf{D}_{\text {tool }}$ & Tool diameter \\
$\mathbf{f u S}_{\mathbf{u S}}$ & Ultrasonic frequency \\
$\mathbf{f}_{\mathbf{z}}$ & Feed per tooth \\
$\mathbf{n}_{\text {tool }}$ & Spindle speed \\
$\mathbf{S a}$ & Arithmetic mean height \\
$\mathbf{S d r}$ & Developed interfacial area ratio \\
$\mathbf{v}_{\mathbf{c}}$ & Cutting speed \\
$\mathbf{\mathbf { f } _ { \mathbf { f } }}$ & Feed \\
$\mathbf{v} \mathbf{U S}$ & Maximum speed of the oscillation \\
$\boldsymbol{\alpha}$ & Clearance angle \\
$\boldsymbol{\lambda}$ & Wavelength of the oscillation \\
\hline
\end{tabular}

\section{Introduction}

The high hardness and chemical inertness of diamond coatings lead to a high interest in use as forming tool coating. Most of the forming tools are made of steel, so that especially the coatability of steel by a polycrystalline diamond coating would rise the range of fields of application a lot.

The deposition of polycrystalline diamond coatings onto steel has already been researched by various scientists [1], but is still challenging due to the large mismatch in thermal expansion coefficient. Direct deposition of polycrystalline diamond onto steel substrates was investigated by Buijnsters et al. [2], with the conclusion that diffusion barrier layers are essential in the deposition of high-quality and adherent polycrystalline diamond coatings on steel. Several different materials that could serve as a diffusion barrier have been investigated, such as among others $\mathrm{CrN}$ [3], $\mathrm{TiC} / \mathrm{TiN}$ [4], and SiC [5]. The thickness of the diffusion barrier varies in the different researches. Buijnsters et al. [3] deposited successfully a $1.5 \mu \mathrm{m}$ thick polycrystalline chemical vapour deposition (CVD)-diamond coating on high-speed steel of the quality no. 1.3207 with a $2.5 \mu \mathrm{m}$ thick chromium nitride interlayer. They used a CVD-diamond deposition temperature of $650^{\circ} \mathrm{C}$. By the use of the same process conditions and coating system an AISI-type 316 stainless steel substrate could not be diamond coated without delamination. This shows that the type of steel has a strong impact on the coatability.

Using a $20 \mu \mathrm{m}$ thick CrN intermediate layer Glozman et al. deposited a $2 \mu \mathrm{m}$ thick diamond coating on steel specimens by HF-CVD. In subsequent tests on the adhesive strength, delamination took place between the steel substrate and the intermediate layer. [6]

Kellermann et al. [1] showed on $41 \mathrm{Cr} 4$ steel specimen with a chromium carbide intermediate layer, that austenite

\footnotetext{
* Corresponding author: prieske@bias.de
} 
to ferrite transformation has a high impact on the residual stress and thereby on the delamination of the coating. Diamond coatings deposited at temperatures underneath the first temperature of phase transformation $\mathrm{A}_{\mathrm{C} 1}\left(738^{\circ} \mathrm{C}\right)$ caused cracks and flaking. Higher deposition temperatures between $760{ }^{\circ} \mathrm{C}$ and $920{ }^{\circ} \mathrm{C}$ reduced the residual stress in the diamond coating due to the austenite to ferrite transformation in the steel substrate which results in a volume expansion during cooling down.

All processes applied for the successful deposition of polycrystalline diamond coatings onto steel substrates use a vacuum chamber. According to the dimensions of, for example, forming tools and their complex geometries, a chamber-free deposition process is required for the application of local wear protection.

Multiple studies examine the impact of the substrate surface microstructure on the adhesion strength of CVD-diamond coatings. The term surface microstructure is used in this publication with the meaning of a defined surface topography. The effect of the substrate roughness on the CVD-diamond coating of $\mathrm{Si}_{3} \mathrm{~N}_{4}$ specimens was reported by Amaral et al. The combination of different pre-treatments and seeding processes led to the conclusion that surfaces roughened by plasma etching increase the layer adhesion of the CVD-diamond coating due to "anchoring effects", whereby no closer information on the substrate roughness was given. [7] Singh et al. observed that the generation of a three-dimensional (3D) thermally and compositionally graded interface between diamond and the substrate material leads to improved adhesion of the diamond film [8]. Under Wako et al. investigations were carried out regarding the adhesion or the layer adhesion of CVD-diamond coating on differently pre-treated molybdenum specimens $(99.9 \%$ Mo) [9]. The molybdenum substrates were pre-treated by polishing and grinding to achieve both different roughness and anisotropic as well as isotropic surface structure. An ultrasonic cavitation test under water exposed the CVD-diamond coating (thickness $2.5 \mu \mathrm{m}$ ) to stress. The substrates with the higher surface roughness (Ra $0.32 \mu \mathrm{m}$ and $0.23 \mu \mathrm{m}$ ) showed a better layer adhesion basis. In addition, it was concluded from the crack growth parallel to the surface that anisotropic structures pass it in one direction only, while isotropic structures tend to exhibit circular layer delamination in this type of stress. [9] Investigations on the influence of the surface roughness on the layer adhesion were also done under $\mathrm{Xu}$ et al. In this case, CVD-diamond coatings were deposited on cemented carbide substrates with smooth (Rq $0.04 \mu \mathrm{m})$ as well as blasted ( $\mathrm{Rq} 0.27 \mu \mathrm{m})$ surfaces using a $\mathrm{Cr}-\mathrm{CrN}$ interlayer system. While the diamond coating of the specimens without any interlayer system flaked off directly on cooling, adherent CVD-diamond with a thickness of approx. $9 \mu \mathrm{m}$ was deposited on both with diffusion barriers. In a Rockwell $\mathrm{C}$ indentation test the diamond coating without surface pre-treatment showed significantly poorer attachment (delamination at the interface to the interlayer), suggesting that increased surface roughness prior to CVD-diamond coating enhances layer adhesion. [10] Gomez et al. found in cutting experiments that a preferred direction of the substrate roughness, resulting from the delivery state or the finishing of the cemented carbide inserts, has a negative impact on the subsequent adhesion of the CVD-diamond layer $(>20 \mu \mathrm{m})$ under mechanical stress [11]. By means of a more intensive mechanical interlocking and a mechanically graded transition from the substrate material into the CVD-diamond coating, the compressive stresses in the transitional area can be significantly reduced compared to a smoother substrate surface. This was found by Lee et al. in their investigations in the CVD-diamond coating of laser induced micro-rough surfaces on cemented carbide substrates. [12]

In recent studies it was shown that diamond crystals can be deposited on steel with a silicon carbide interlayer by a laser induced plasma CVD process without a process chamber [13]. But as soon as a closed polycrystalline CVD-diamond coating is formed at the process temperature of $1100{ }^{\circ} \mathrm{C}$ the diamond coating delaminates during the cooling down phase after the process. To lower the impact of thermal expansion of the steel substrate, the deposition temperature of the process could be reduced to $700{ }^{\circ} \mathrm{C}$. The investigations examine the impact of the surface microstructure, especially regarding the surface roughness and isotropy on preventing a delamination of the diamond coating.

\section{Methods}

The specimens were made of the tool steel 1.2379 (X135CrMoV12) in the soft annealed state (255 HB / approx. $268 \mathrm{HV}$ ) which is for example used for forming tools. Seven different microstructures on the surfaces of the steel specimens were produced. One is the as-delivered condition with a ground surface. A polished surface was prepared by grinding with 1200-grit abrasive paper and subsequent polishing by a diamond suspension of $3 \mu \mathrm{m}$ grain size. Two different surface microstructures were produced by a blasting process of polished substrates by the company Oerlikon Balzers. A blasting by glass beads with a pressure of 4 bar as well as a corundum blasting with a pressure of 3 bar.

To generate reproducible surface microstructures in the range of the surface roughness, ultrasonic vibration assisted milling (UVAM) is a suitable process. This process was used to produce three different surface microstructures. Due to its kinematics, the microstructure is adequately predictable. Also it is possible, to vary the geometric properties regarding the isotropy as well as the aspect ratio or the mean height of the surface structure by adjusting various process parameters.

Face milling with vibration superimposition in the direction of the tool axis could be determined by a defined trajectory of the tool cutting edge. This results from the (ultrasonic) oscillations per revolution as well as the cycloidal trajectory, which reflects the rotational speed of the tool via a translatory feed (schematically shown in Fig. 1). On the basis of this trajectory, the simulation of the resulting surface microstructure takes place. 


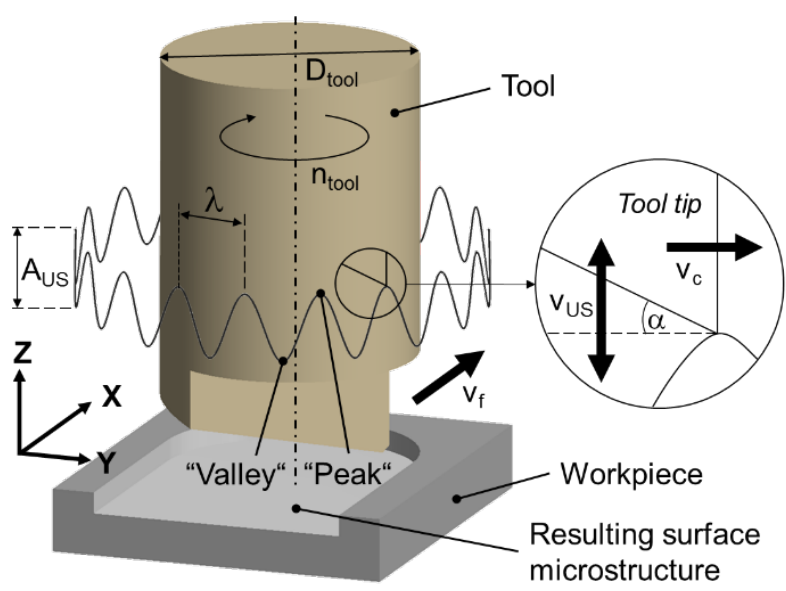

Fig. 1. Kinematics of ultrasonic vibration assisted face milling.

A simulation model was developed in MATLAB to calculate the surface microstructure of ultrasonic vibration assisted face milling. Therefore, a virtual tool was intersected along a defined trajectory with the virtual workpiece. This so called "kinematic model" does not consider dynamic effects nor physical effects such as burr formation, flaking or temperatures. Hence, a dexel model is sufficient for the volumetric representation of both the tool and the workpiece with regard to the spatial accuracy. Each dexel describes a discrete point with one height value aligned over a regular grid in the X-Y-plane. The advantage of this form of spatial discretisation is that due to the two-dimensional, equidistant dot distribution, the storage requirement increases not during the simulation and only quadratically with the increasing number of dexel points. Additionally, the surface simulation tool allows the integration of various tool geometries and kinematic paths. For the calculation, only the engaged part of the tool is relevant, which is initially constructed by means of a CAD software. The description of the tool movement along the trajectory was temporally discretized, too. In [14] the approach for the stepwise calculation of the tool position and orientation as a path vector was presented. Considering the requirement for a time efficient simulation, the computational effort is reduced by the simulation of one single rotation, which was afterwards patterned in the distance and the direction of the feed. This method allows an implementation and a variation of UVAM kinematics. In this way, the effects of displacement as well as re-cuts can be simulated and evaluated.

The experimental investigations were carried out at a high precision machining centre (KERN Pyramid Nano). A common transducer (Hielscher UIP 2000 hdT) was used to generate the ultrasonic vibration. According to Fig. 2 the set-up was clamped on the machine table. Inside the transducer are inert masses, a bolt for preload, piezoelectric discs and electrodes. The electrodes transfer the voltage to the piezoelectric discs and the discs transform the applied electric field into a linear motion using the inverse piezoelectric effect.

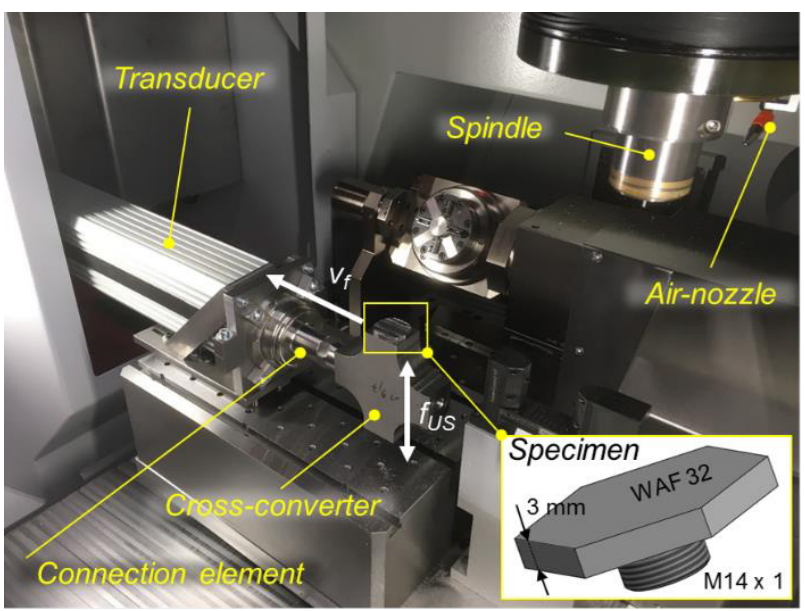

Fig. 2. Experimental set-up for UVAM.

To reduce the mass of the specimens and ensure the resonant vibration mode the specimens were designed only with a very small height (3 mm, Fig. 2$)$. The direction of the vibration should coincide with the rotational tool axis to generate the desired microstructure on the specimen's surface. Thus, a cross-converter was required. On the one hand, the direction of the oscillation was turned $90^{\circ}$. This is based on the eigenfrequency of the converter: an elongation in the horizontal direction will result in a contraction in the vertical direction. On the other hand, the converter carries the specimen by a screw connection (thread M14 x 1, Fig. 2).

The minimum amplitude ( $A_{U S}$ ) which could be set by the transducer was about $4.5 \mu \mathrm{m}$. To achieve an aspect ratio of approx. $1 / 4$ of the microstructure, this results in a structural distance of about $18 \mu \mathrm{m}$ : in one direction, it represents the feed, in the direction of the cutting speed it corresponds to the wavelength $\lambda$. For this reason it was necessary to use tools with a special geometry to prevent a collision between the tool's minor flank face and the generated surface microstructure, which is explained in detail in [14]. With this geometric specifications, the tool have a clearance angle of $40^{\circ}$ and therefore, to ensure the stability of the cutting edge, a negative rake angle $\left(-10^{\circ}\right)$. The angle of the minor cutting edge is $15^{\circ}$. To protect the sharp cutting corner they have a very small chamfer $\left(14 \mu \mathrm{m} \times 60^{\circ}\right)$. Those geometric specifies of the tool tip are shown in Fig. 3.
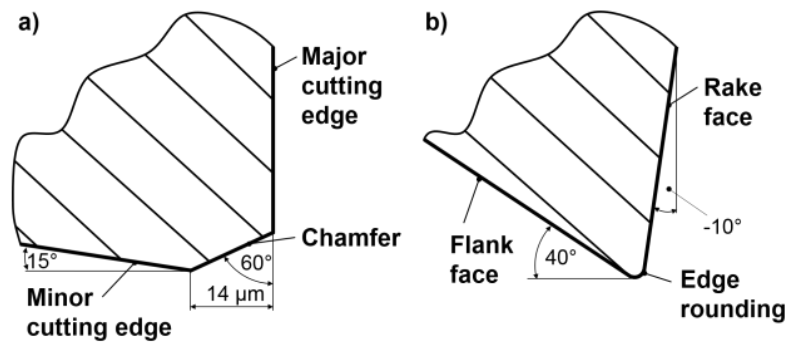

Fig. 3. Schematical tool tip shown in tool reference plane (a) and tool orthogonal plane (b) 
Only single-edged tools were used in order to exclude a possible height offset between cutting edges due to the manufacturing process. The cemented carbide end milling cutters with a diameter of $D_{\text {tool }}=6 \mathrm{~mm}$ were manufactured by voha-tosec Werkzeuge $\mathrm{GmbH}$ and have a TiAlN / TiSiN coating system ("Hardlox"). The "wavelength" $(\lambda)$ of the microstructure in the circumferential direction is defined by the ratio of the rotational speed and the oscillation frequency. Due to a nearly constant eigenfrequency, this ratio could be determined by the cutting speed. According to the maximum ultrasonic speed, the amplitude and the clearance angle, the cutting speed $\left(\mathrm{v}_{\mathrm{c}}, \min =21 \mathrm{~m} / \mathrm{min}\right)$ was calculated by (1):

$$
\mathrm{V}_{\mathrm{c}}, \min =\mathrm{V}_{\mathrm{US}} / \tan 40^{\circ}=\left(2 \cdot \pi \cdot \mathrm{f}_{\mathrm{US}} \cdot \mathrm{A}_{\mathrm{US}}\right) / \tan 40^{\circ} .
$$

Slight deviations of the measured values of the amplitude are attributed to the transmission characteristics of the oscillation system. The vibration amplitude was transformed in the orthogonal direction (parallel to the rotational tool axis) with negligible vibration in the parallel direction (in feed direction, but only in the sub $\mu \mathrm{m}$ range). During the process, one additional piezoelectric disc is used as a sensor element to ensure operation in resonance mode. The resonance frequency fus was about $19.25 \mathrm{kHz}$. Additionally, two more process parameters were investigated. These are presented in Table 1. The specimens include the two parameters $A_{U S}$ (ultrasonic amplitude: peak-to-peak) and the wavelength $\lambda$.

Table 1 Experimental plan and machining parameters

\begin{tabular}{|c|c|c|c|c|c|}
\hline$\#$ & $\begin{array}{c}\text { Aus } \\
{[\boldsymbol{\mu m}]}\end{array}$ & $\begin{array}{c}\mathbf{f U S} \\
{[\mathbf{k H z}]}\end{array}$ & $\begin{array}{c}\mathbf{f}_{\mathbf{z}} \\
{[\boldsymbol{\mu \mathbf { m } ]}]}\end{array}$ & $\begin{array}{c}\mathbf{v} \mathbf{c} \\
{[\mathbf{m} / \mathbf{m i n}]}\end{array}$ & $\mathbf{A R}$ \\
\hline UVAM 4.5 18 & 4.5 & & 18 & 21 & 0.25 \\
\hline UVAM 4.526 & 4.5 & \multirow{2}{*}{19.25} & 26 & 30 & 0.17 \\
\cline { 1 - 3 } \cline { 4 - 6 } UVAM 6.5 26 & 6.5 & & 26 & 30 & 0.25 \\
\hline
\end{tabular}

All steel specimen are coated by the company Oerlikon Balzers with a $2.4 \mu \mathrm{m}$ thick chromium nitride $\left(\mathrm{BALIQ}^{\circledR}\right.$ CRONOS) layer by high-power impulse magnetron sputtering (HIPIMS) in one batch. The thickness and the type of coating were chosen regarding to the publication of Buijnsters et al. [3]. A high CrN interlayer thickness of $20 \mu \mathrm{m}$ as used by Glotzman et al. [6] was avoided to be able to evaluate the impact of the microstructure on the adhesion of the diamond coating. Diamond nucleation was carried out with a dispersion consisting of $200 \mathrm{ml}$ of isopropanol and $210 \mathrm{mg}$ of diamond powder with an average crystal size of $0.25 \mu \mathrm{m}$ to $0.50 \mu \mathrm{m}$ from the company Microdiamant AG. The substrates were put into the dispersion for ten minutes in an ultrasonic bath and subsequently into isopropanol for three minutes.

A $\mathrm{CO}_{2}$ laser-based plasma CVD process, shown in Fig. 4 was used at atmospheric pressure without a vacuum chamber for the deposition of polycrystalline CVD-diamond coatings. A $6 \mathrm{~kW}$ high-power $\mathrm{CO}_{2}$ laser with a wavelength of $10.6 \mu \mathrm{m}$ was used for energy supply of the plasma jet. The ignition chamber was flooded by argon gas through a gas nozzle. The ignition of the plasma flame was achieved by thermionic emission through inserting a tungsten lanthanum ignition rod into the laser focus. This generates an optical breakdown. The laser radiation that was not absorbed by the plasma flame was directed to a water-cooled beam trap. After the ignition of the argon plasma flame, the process gases 0.02 standard litres per minute (slm) methane and $1.98 \mathrm{slm}$ hydrogen, which are required for CVD synthesis of polycrystalline diamond, are supplied.

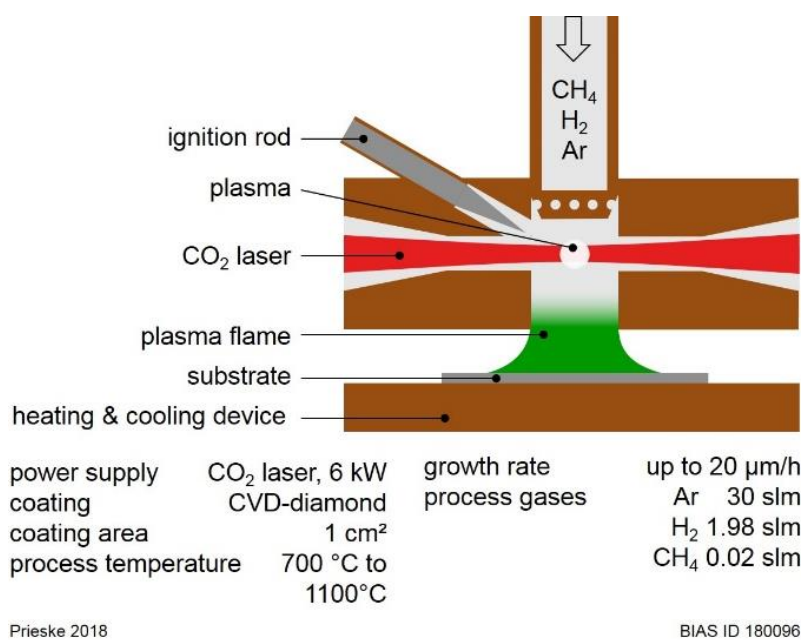

Fig. 4. Schematic layout of the laser induced plasma CVD process at atmospheric pressure.

To ensure a constant deposition temperature over the whole deposition time, a feedback control was implemented, which regulates the laser power according to the measured substrate temperature of the IMPAC pyrometer IGAR 12-LO. Detailed information of the implementation of the feedback control are published in [15]. For temperature monitoring, three pyrometer were used, IMPAC pyrometer IGAR 12-LO, IP 140 and IGA 10. To determine the emission coefficient for each pyrometer, one of the $\mathrm{CrN}$ coated steel substrates was heated up to $800^{\circ} \mathrm{C}$ by a ceramic hot plate, which was measured by a thermocouple. The emission coefficients were set to 0.34 for pyrometer IGAR 12-LO, to 0.37 for pyrometer IP 140 and to 0.25 for pyrometer IGA 10 , so that each of them measures $800{ }^{\circ} \mathrm{C}$.

Scanning electron microscopy (SEM) (Carl Zeiss Microscopy EVO MA-10) and 3D laser microscopy (Keyence VK-9710 and Keyence VK-9700) were used to take images of the pre-treated as well as coated surfaces and to determine the roughness parameters according to ISO 25178 part 2 and 3 on a measuring area of $0.5 \mathrm{~mm} \mathrm{x}$ $0.5 \mathrm{~mm}$. This ensures that a minimum of five form elements in both the X-direction and the Y-direction are included in the calculation of the surface parameters. For the roughness analysis an S-Filter of $2 \mu \mathrm{m}$ and an L-Filter of $0.5 \mathrm{~mm}$ was used

The characterisation of both the milled and the simulated surface microstructure of the UVAM specimens was carried out using the surface analysis software VK Analyzer. The selected measuring field was located centric along the milling path. In order to remove inclination deviations, the measured surfaces of the specimens were aligned by means of a subtraction method 
and a form filter (2nd degree polynomial) was used to eliminate shape deviations.

Element analysis was done by an energy-dispersive X-ray spectroscope (EDX) (Bruker Nano GmbH XFlash Detector 610M). Raman spectroscopy (Renishaw system 1000 ) with an excitation wavelength of $514 \mathrm{~nm}$ was used to determine diamond and graphite. The existence of diamond was evidenced by the measurement of the first order Raman line of diamond at $1332 \mathrm{~cm}^{-1}$ [16]. Cryofractures were produced by eroding a predetermined breaking point into the steel substrate up to $0.5 \mathrm{~mm}$ underneath the coating area. Afterwards the specimen was cooled down by liquid nitrogen and broken into two parts. The hardness of the steel specimen was measured by a Vickers hardness test (Durascan 50G5) according to DIN EN ISO 6507-1.

Dilatometer measurements were performed with a quenching dilatometer DIL 805A according to ASTM A1033-10. The steel specimens for the dilatometer tests were used in form of pipes and had a length of $10 \mathrm{~mm}$, an outer diameter of $4 \mathrm{~mm}$ and an inner diameter of $3 \mathrm{~mm}$.

One batch of steel specimens was coated at a process temperature of $840{ }^{\circ} \mathrm{C}$ with a coating thickness of $8 \mu \mathrm{m}$ and another one at $700^{\circ} \mathrm{C}$ with a thickness of $1 \mu \mathrm{m}$. $700{ }^{\circ} \mathrm{C}$ was the lowest achievable temperature by the use of a water cooled copper specimen holder. The cooling down rate after deposition was $33 \mathrm{~K} / \mathrm{s}$ from $840{ }^{\circ} \mathrm{C}$ to $350^{\circ} \mathrm{C}$ measured by the pyrometer IGAR $12-\mathrm{LO}$. Cooling down was done under a protective argon atmosphere to prohibit oxidation.

\section{Results}

In the visual comparison of the UVAM microstructured surfaces with the simulated, it was found that the milled surfaces correspond to those simulated without re-cutting, but rotated by $180^{\circ}$. It seems likely that the microstructure results entirely from the re-cut, visible on individual form elements. The valleys as well as the peaks show a similar preferred direction. This could be attributed to an elastic material spring back, whereby the pre-cut compresses the material thus the re-cut enters full material. In addition, a slight displacement of the microstructure occurs (Fig. 5, down). This results from a non-controllable, non-integer ratio of the rotational speed and the oscillation frequency. The two variants of the simulation in Fig. 5 show the case without (SIM_1) or with a maximum structural displacement (SIM_2).
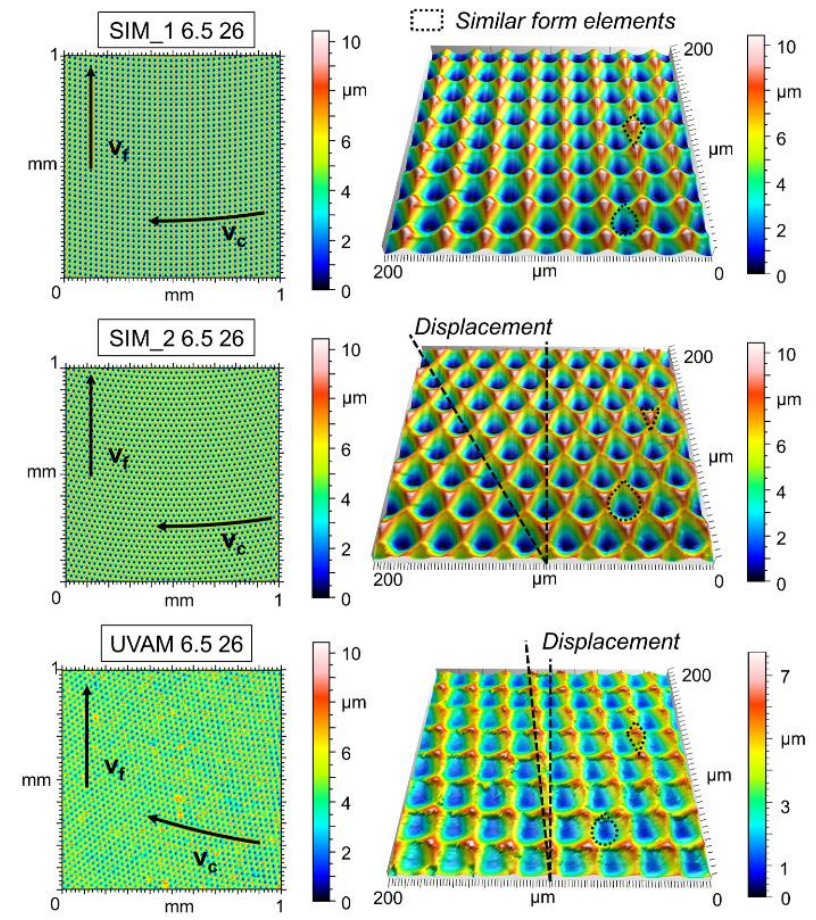

Fig. 5. Visual surface comparison of SIM_1 6.526 (top), SIM_2 6.526 (middle) and UVAM 6.526 (down).

Furthermore, it is shown, that the profile height of the generated surface is smaller than the simulated height. This could be due to the damping of the amplitude by the tool intervention. The quantitative comparison of the surface parameters $\mathrm{Sa}$ and $\mathrm{Sdr}$ confirms the considerations of the surface design (Fig. 6). It could be noted that the smallest value for the arithmetic mean height corresponds with the smallest developed interfacial ratio (for the three with UVAM generated surfaces). The highest value for the developed interfacial area ratio of the specimens (UVAM 6.5 26) results form a higher amplitude.

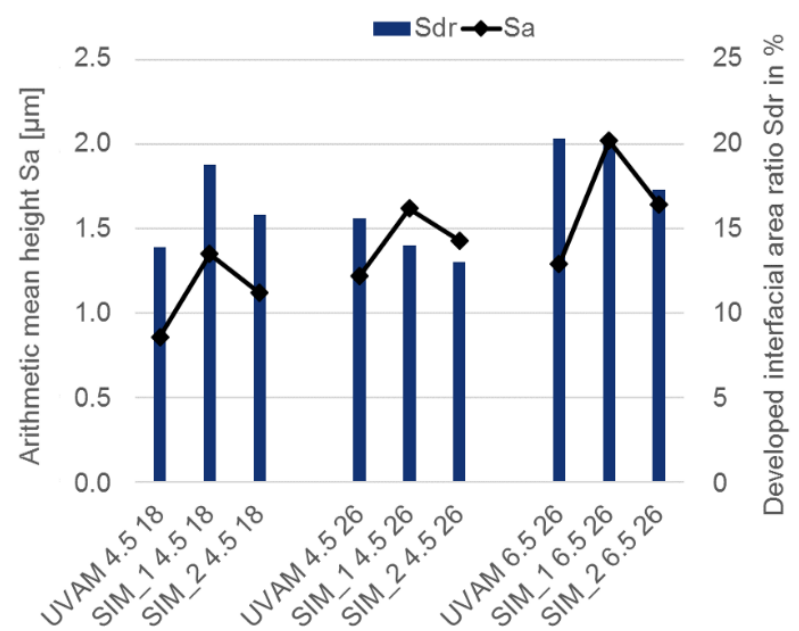

Fig. 6. Results of the surface analysis of the simulated as well as with UVAM generated surfaces.

Although the qualitative (as well as the quantitative) accordance between the designed, simulated and experimentally manufactured surface microstructure is sufficient, it has to be noted that this only applies for the 
middle area of the milled path. In the overlapping area, the microstructure is distorted and this leads to strongly anisotropic areas (Fig. 7). In addition to the microstructure, further elements on the surface, such as burr formation, occur.
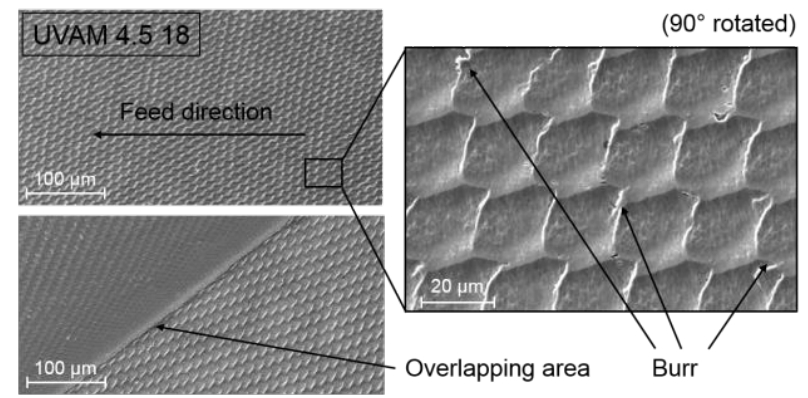

Fig. 7. SEM micrographs of a surface generated with UVAM.

In Fig. 8 differently manufactured microstructures coated by a chromium nitride layer are shown as SEM micrographs as well as the measured $\mathrm{Sa}$ and Sdr values. Both parameters vary over a wide range from the very smooth polished surface with $\mathrm{Sa}=0.1 \mu \mathrm{m}$ and $\mathrm{Sdr}=2 \%$ to the rough corundum blasted surface with $\mathrm{Sa}=3.0 \mu \mathrm{m}$ and $\mathrm{Sdr}=297 \%$. In comparison to Fig. 6 the developed interfacial area ratio (Sdr) values increase and the $\mathrm{Sa}$ values decrease due to the chromium nitride coating. EDX measurements of the chromium nitride coating detected 47 at. $\%$ nitrogen and 53 at. $\%$ chromium, which verifies a chromium nitride coating.

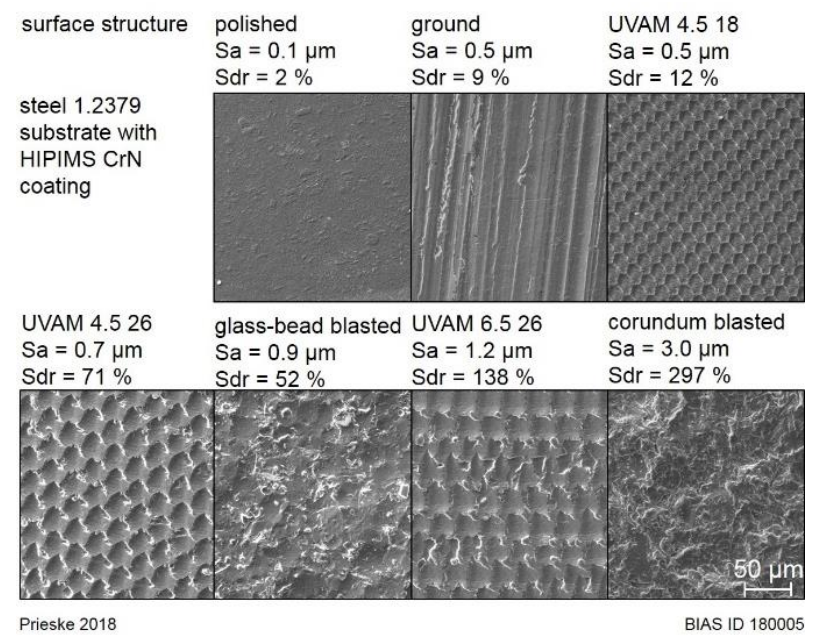

Fig. 8. SEM micrographs of the different microstructures realized on steel substrates and coated by a chromium nitride layer.

The result of the dilatometer measurement shown in Fig. 9 a) with a slower heating rate of $2 \mathrm{~K} / \mathrm{s}$ shows an austenite to ferrite transformation and thereby a nonlinear change in length. The temperatures of phase transformation $\mathrm{A}_{\mathrm{C} 1}$ and $\mathrm{A}_{\mathrm{C} 3}$ are measured as $840{ }^{\circ} \mathrm{C}$ and $871^{\circ} \mathrm{C}$. In Fig. 9 b) the test parameters are adapted to the process conditions, with a heating from room temperature to the deposition temperature in 2.5 minutes and a subsequent holding time of 40 minutes at the deposition temperature. The tests show that a holding temperature of $840^{\circ} \mathrm{C}$ leads to the smallest length change of $0.86 \%$. With the LaPlas CVD process $700{ }^{\circ} \mathrm{C}$ is the lowest achievable temperature, where a diamond coating can be deposited. During the heating process of the dilatometer test the length change at $700{ }^{\circ} \mathrm{C}$ shows a length change of $0.93 \%$.
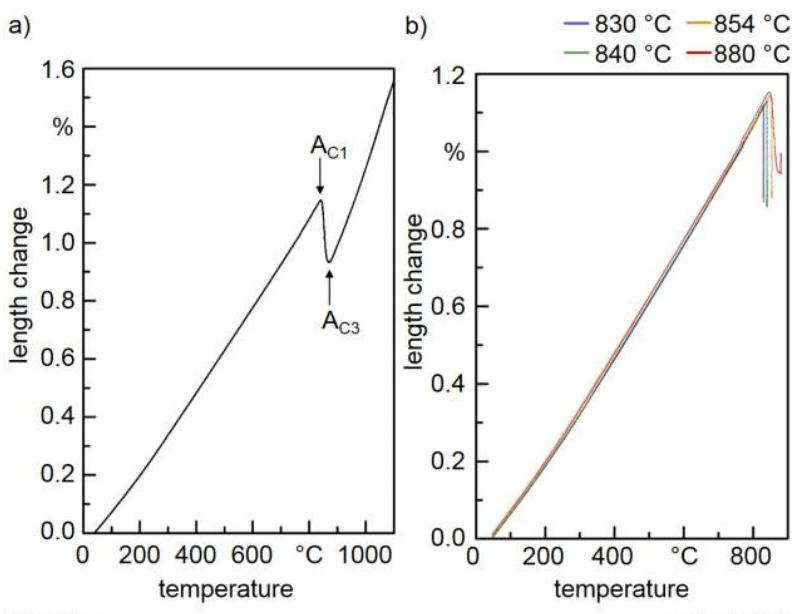

Prieske 2018

BIAS ID 180998

Fig. 9. Dilatometer measurements of 1.2379 steel specimen a) with a heating rate of $2 \mathrm{~K} / \mathrm{s}$ up to $1100{ }^{\circ} \mathrm{C}$ and b) with a heating rate of $7 \mathrm{~K} / \mathrm{s}$ and different holding temperatures for 40 minutes.

Fig. 10 shows the result of the local CVD-diamond deposition at $840{ }^{\circ} \mathrm{C}$ with a thickness of $8 \mu \mathrm{m}$. In the photography of the coating, the bright grey area is the $\mathrm{CrN}$ layer, where the diamond coating delaminated. The dark grey area is the remaining diamond coating. The black box shows the position of the measured height profile. The scale of the height profile in Fig. 8 and Fig. 12 is individually chosen to show the optimum contrast, with the low structures in blue colour and the high structures (usually the diamond coating) in red. The four microstructured specimens with the lowest roughness (Fig. 10 left side) led to a delamination of the diamond coating in form of a diamond foil, so that nearly no diamond is left on the substrate. The glass-bead blasted substrate led to a flake like delamination. The UVAM 6.526 specimen shows that especially in the overlap area with a distorted microstructure a complete delamination occurs. The diamond coating on the corundum blasted specimen looks as a closed diamond coating in the macroscopic image. 

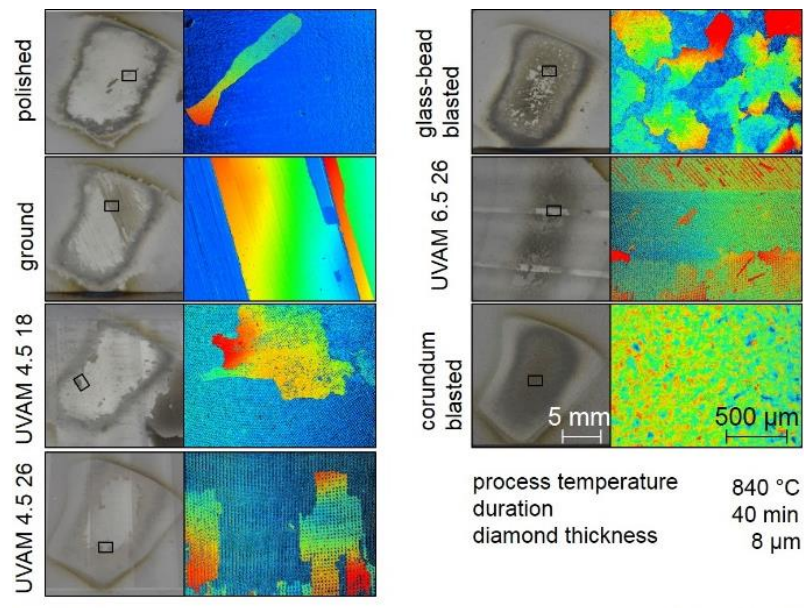

Prieske 2018

BIAS ID 180036

Fig. 10. Photography and height profile of the diamond coating deposited at $840{ }^{\circ} \mathrm{C}$.

A higher magnification of the remaining diamond coating on the substrate is shown in Fig. 11. On each image the polycrystalline character of the coating can be seen.

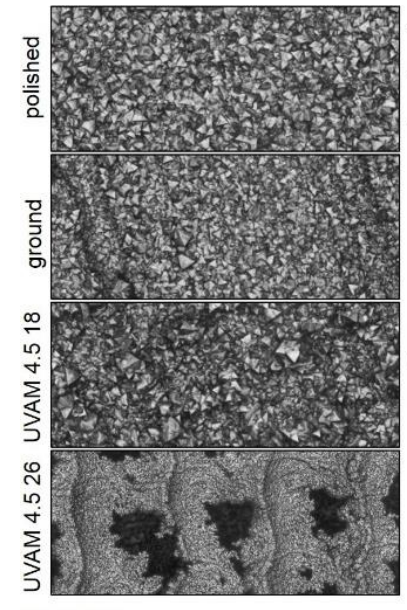

Prieske 2018

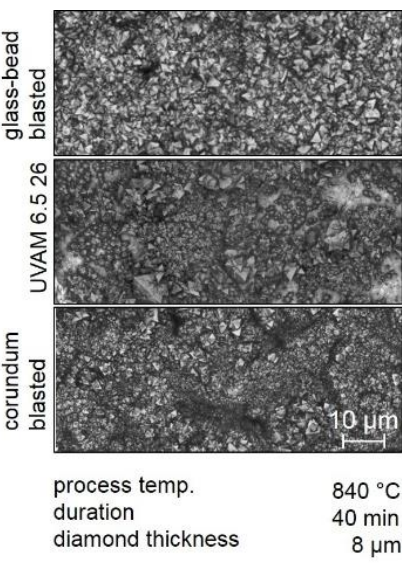

BIAS ID 180037
Fig. 11. Microscopic images at high magnification of the diamond coatings deposited at $840{ }^{\circ} \mathrm{C}$, which show the crystalline structure.

The two structured specimens UVAM 4.526 and UVAM 6.526 show that in the valleys of the surface structure the diamond coating is not a closed layer. Especially the higher peak to valley height of specimen UVAM 6.526 leads to the growth of large diamond crystals on the peaks and just small diamond crystals in the valleys, as it is marked in Fig. 12 on the right image. The diamond coating on the corundum blasted substrate has small uncoated or delaminated areas as can be seen in Fig. 13. The white dots in Fig. 13 a) represent the $\mathrm{CrN}$ coating, which is not coated by diamond as can be seen in the detailed image in Fig. 13 b) and was verified by an EDX measurement.

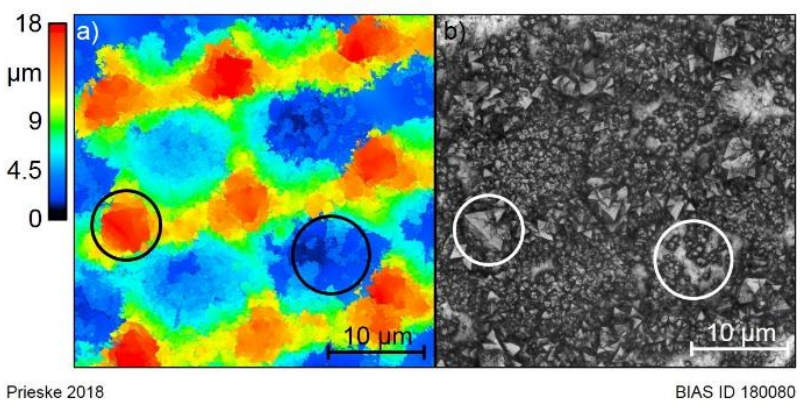

Fig. 12. Diamond coating deposited at $840{ }^{\circ} \mathrm{C}$ on an UVAM 6.526 substrate a) as a height profile and b) microscope image on the same position.

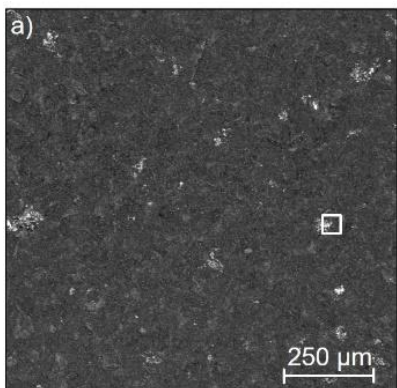

Prieske 2018

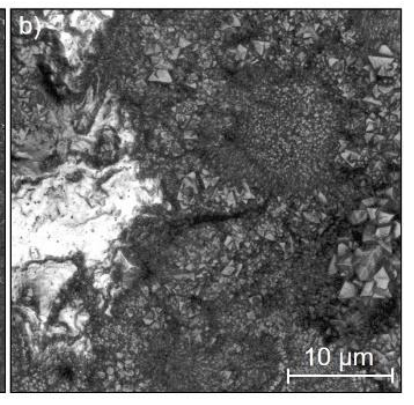

BIAS ID 180081
Fig. 13. a) Overview image and b) detailed image (box shown in a) of the diamond coating deposited at $840{ }^{\circ} \mathrm{C}$ on corundum blasted substrate.

Fig. 14 shows the result of the local CVD-diamond deposition at $700{ }^{\circ} \mathrm{C}$ with a thickness of $2 \mu \mathrm{m}$. Compared to the diamond coatings deposited at $840^{\circ} \mathrm{C}$ (Fig. 10) the area of delamination decreases. In the height profiles of all specimen clear delamination can be seen except on the ground and corundum blasted specimen. On the ground substrate a closed diamond layer is deposited with lots of small delaminated areas (black dots in the height profile). The overlap area of the UVAM specimens promotes the delamination of the diamond coating, as can especially be seen in the photography of specimen UVAM 4.518.

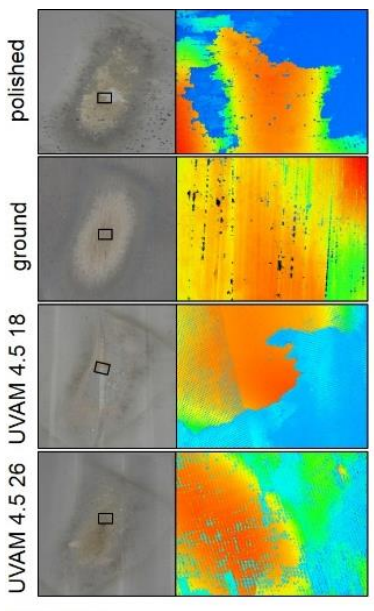

Prieske 2018

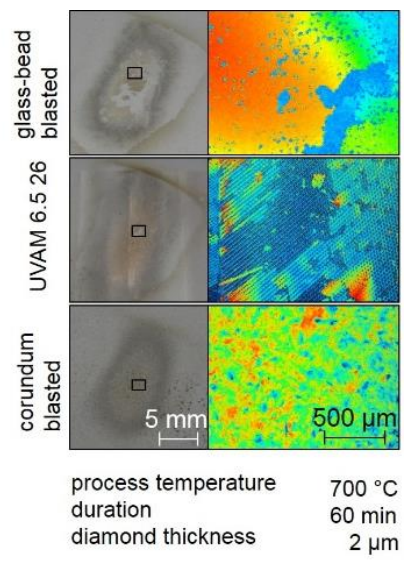

BIAS ID 180038
Fig. 14. Photography and height profile of the diamond coating deposited at $700{ }^{\circ} \mathrm{C}$.

The highly magnified images of the diamond coatings deposited at $700{ }^{\circ} \mathrm{C}$ in Fig. 15 show a nanocrystalline structure. In all images, except of the diamond coating on 
the polished substrate, small delaminated or uncoated areas can be seen, which have a length smaller than $10 \mu \mathrm{m}$.
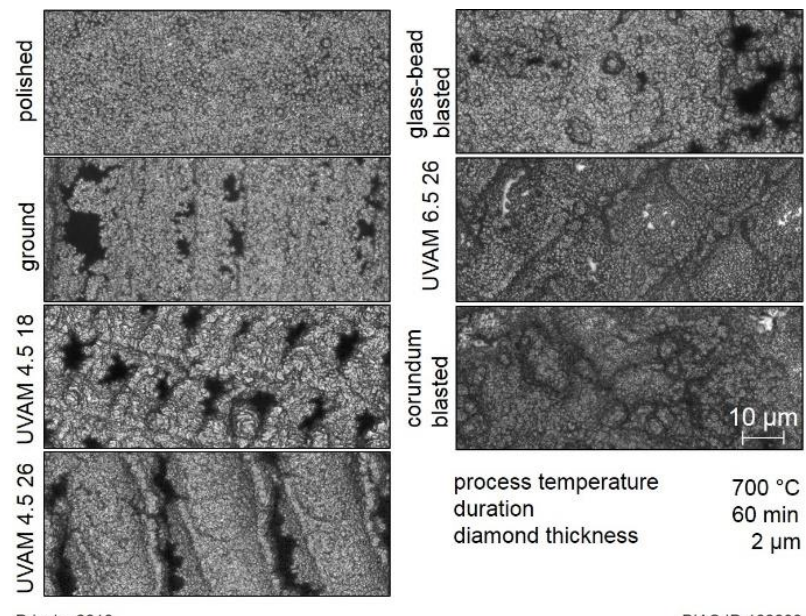

Prieske 2018

BIAS ID 180039

Fig. 15. Laser scanning microscope images at high magnification of the diamond coatings deposited at $700{ }^{\circ} \mathrm{C}$, which show the crystalline structure.

A representative Raman spectrum of a diamond coating deposited at $840{ }^{\circ} \mathrm{C}$ and $700{ }^{\circ} \mathrm{C}$ is shown in Fig. 16. The spectrum of the coating deposited at $840{ }^{\circ} \mathrm{C}$ shows the peak at $1332 \mathrm{~cm}^{-1}$, which proofs residual stress free microcrystalline diamond [16]. No residual stress is measured, because the measurement is done on a diamond coating which is partly delaminated. The peak at $1560 \mathrm{~cm}^{-1}$ is the so called G-peak [17] which shows that the coating also has a graphitic content. The peak at $1190 \mathrm{~cm}^{-1}$ can be related to incorporated nitrogen in the diamond coating, which is introduced by the $\mathrm{CrN}$ interlayer. Zhang et al. [18] detected an increase of two peaks at $1190 \mathrm{~cm}^{-1}$ and $1550 \mathrm{~cm}^{-1}$ with increasing nitrogen content in the diamond coating.

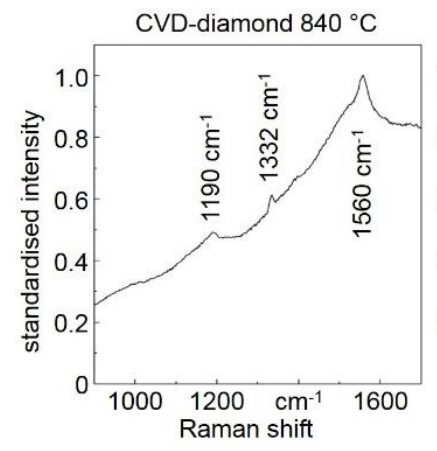

apparatus RM1000 Raman spectroscope lllumination source argon ion laser Prieske 2018

(n) $10 \mathrm{~mW}$

Fig. 16. Raman spectra of the diamond coating deposited at $840{ }^{\circ} \mathrm{C}$ (left) and at $700{ }^{\circ} \mathrm{C}$ (right).

The cryofractures shown in Fig. 17 are produced after the diamond deposition. It can be seen, that the $\mathrm{CrN}$ interlayer has a coating thickness of $2.4 \mu \mathrm{m}$. Even on specimen UVAM 6.526 the $\mathrm{CrN}$ coating is very homogenous. The diamond coating delaminates by producing the cryofracture. Just at the boarder of the coated area on the polished substrate Fig. $17 \mathrm{~b}$ ) the diamond coating remained.

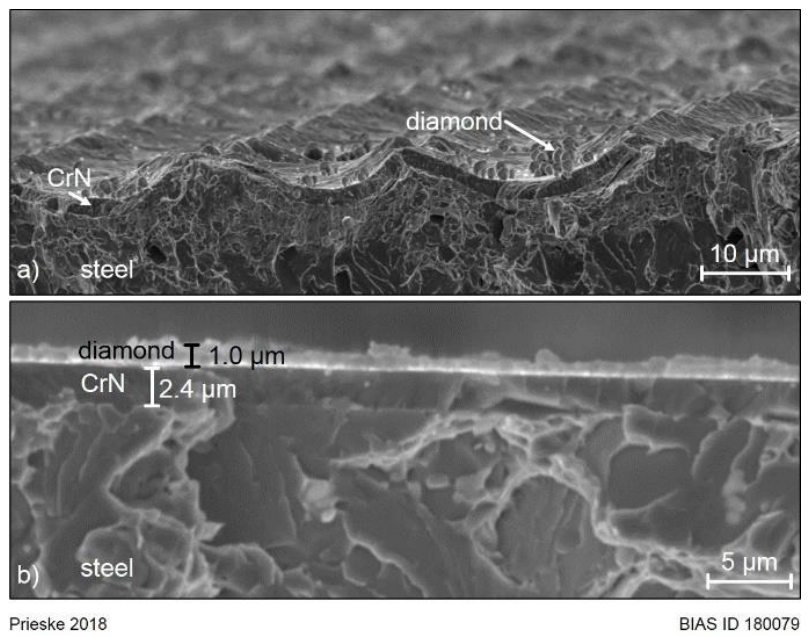

Fig. 17. a) Cryofracture of UVAM 6.526 specimen diamond coated at $840{ }^{\circ} \mathrm{C}$ and b) cryofracture of the polished specimen after diamond coating at $700{ }^{\circ} \mathrm{C}$.

Hardness measurements in Fig. 18 show that the steel is in a soft annealed state after the deposition process, with a hardness of approximately $220 \mathrm{HV} 0.1$.
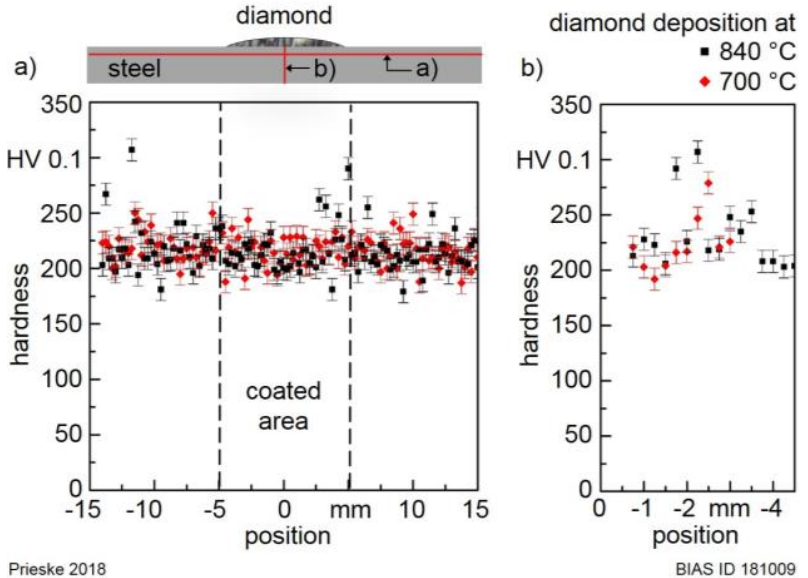

Fig. 18. Hardness measurements of the steel substrate a) parallel and b) perpendicular to the surface after the deposition process at $700{ }^{\circ} \mathrm{C}$ and $840{ }^{\circ} \mathrm{C}$.

\section{Discussion}

CVD-diamond deposition of steel provides several challenges. To enable the coatability of steel by a diamond layer a diffusion barrier is necessary, which prevents the diffusion of carbon into the steel specimen and the diffusion of iron into the diamond coating. The investigations show, that the used HIPIMS chromium nitride coating with a thickness of $2.4 \mu \mathrm{m}$ successfully worked as a diffusion barrier and has a high adhesion to the steel substrate. In all cases the delamination took place at the interface between $\mathrm{CrN}$ interlayer and diamond coating.

The used tool steel 1.2379 has a thermal linear expansion coefficient of $13.0 \cdot 10^{-6} \mathrm{~m} /(\mathrm{m} \cdot \mathrm{K})$ in the temperature range from $20^{\circ} \mathrm{C}$ to $400{ }^{\circ} \mathrm{C}$ [19]. Diamond has a thermal expansion coefficient between 
$1.0 \cdot 10^{-6} \mathrm{~m} /(\mathrm{m} \cdot \mathrm{K})$ and $4.5 \cdot 10^{-6} \mathrm{~m} /(\mathrm{m} \cdot \mathrm{K})[1]$. This leads to a big mismatch of thermal expansion coefficients and induces large residual stresses.

The delamination can be influenced by the surface microstructure. The diamond coating deposited at $840{ }^{\circ} \mathrm{C}$ with a coating thickness of $8 \mu \mathrm{m}$ shows larger delamination than the coating deposited at $700{ }^{\circ} \mathrm{C}$ with a thickness of $2 \mu \mathrm{m}$. Fig. 9 shows that the prolongation of the steel specimen is less for a deposition at $840{ }^{\circ} \mathrm{C}$ with $0.86 \%$ than for $700{ }^{\circ} \mathrm{C}$ with $0.93 \%$, which is due to the austenite to ferrite transformation. Uncoated areas in the $2 \mu \mathrm{m}$ thick diamond coatings prevent the generation of high stresses. A higher coating thickness of the diamond coating as well as a closed coated area leads to an increase of the residual stresses. Hardness measurements of the steel after the deposition processes showed that the steel is in annealed condition. The cooling down rate from deposition temperature to room temperature in two minutes would be fast enough for a hardening of the steel sample. That leads to the assumption that the total length change could be lower with a higher deposition temperature than $840{ }^{\circ} \mathrm{C}$ due to the austenite to ferrite transformation in the steel substrate which results in a volume expansion during cooling down in case of a hardening process.

Fig. 10 shows, that the coating adhesion is increased with increasing arithmetic mean height $(\mathrm{Sa})$ to a certain extent. This agrees with the literature cited in the introduction [7-10]. Regarding the coating thickness of $8 \mu \mathrm{m}$ higher roughness values result in a flake-like delamination, with remaining areas of the diamond coating. Whereas low roughness values lead to a delamination of the diamond coating as a foil. The overlap area of UVAM 6.526 reduces the surface roughness (Fig. 7). It can be seen that at the positions of the overlap areas a complete delamination takes place, whereas inside the milling path just local delamination is detected (Fig. 10). Furthermore, the UVAM 6.526 substrate shows that sharp peaks lead to the formation of large diamond crystals (Fig. 12). At the same time the valleys are not coated by a closed diamond layer. This can be explained by a local build-up temperature on the sharp peaks, which results in a local higher diamond growth rate. The diamond coating growth in microwave plasma CVD processes also strongly interacts with mountains, which leads to a reduced diamond growth rate in valleys. To achieve a homogenous coating the chamber pressure is increased, which is not possible in the atmospheric LaPlas CVD process. It is assumed that the higher the peak to valley height is, the higher is the probability that the carbon atoms bind to the larger diamond on the peak rather than to the small diamond crystals in the valley.

In Fig. 13 it can be seen that very high Sa and Sdr values, as achieved by corundum blasting, results in an inhomogeneous diamond coating which varies between nano- and microcrystalline diamond. The size of the delaminated areas on the corundum blasted substrates decrease from around $20 \mu \mathrm{m}$ at $840{ }^{\circ} \mathrm{C}$ to $5 \mu \mathrm{m}$ at $700{ }^{\circ} \mathrm{C}$ (compare Fig. 13 and Fig. 15).

Interestingly, the ground specimen showed quite good results at a deposition temperature of $700{ }^{\circ} \mathrm{C}$. There are small delaminated areas of maximum $10 \mu \mathrm{m}$ diameter of the closed diamond coating, but it did not lead to a complete delamination of the coating, even though it has the second smallest roughness values of the investigated microstructures.

It can be seen that the delamination always takes place in accordance to the structure. The delaminated area of the diamond coating has the form of stripes on ground substrates, of a foil on a polished substrates and is random shaped on the stochastic structures of blasted substrates.

\section{Conclusion}

UVAM can be used to generate defined and reproducible microstructures that can be simulated by a surface prediction tool and varied - in technological limits - in their geometrical properties.

It could be shown that the surface microstructure has a high impact on the interlocking between coating and surface. Low surface roughness values up to $0.9 \mu \mathrm{m}$ lead in case of $8 \mu \mathrm{m}$ thick diamond coatings to a delamination of the diamond coating in form of a diamond foil. Higher roughness values result in a flake-like delamination, with remaining areas of the diamond coating. None of the microstructures investigated in this study was able to overcome the residual stress induced by thermal expansion of the steel substrate in such a way, that it prevents delamination of the coating entirely.

The following conclusions of expedient parameters can be drawn to achieve a closed diamond coating on steel:

- Before diamond deposition of a steel specimen, the thermal expansion of the specific type of steel needs to be investigated. By taking into account that the austenite to ferrite transformation has a strong influence on the prolongation of the steel, the most advantageous deposition temperature and cooling down rate needs to be estimated.

- For the deposition of the steel 1.2379 the deposition temperature needs to be either lower than $650{ }^{\circ} \mathrm{C}$ where the length change of the steel specimen is $0.85 \%$ or higher than $840{ }^{\circ} \mathrm{C}$ with a with hardening of the steel and reducing the thermal expansion.

- Sharp peaks at the microstructured specimen surface should be avoided due to local build-up temperature, which leads to an inhomogeneous diamond coating thickness.

- A certain roughness higher than $\mathrm{Sa} 0.1 \mu \mathrm{m}$ supports the adhesion.

\section{Acknowledgements}

This work was supported by the Deutsche Forschungsgemeinschaft (DFG) under contract no. VO 530/75-2 which the authors gratefully acknowledge. We would like to thank Oerlikon Balzers for the support regarding the surface preparation and $\mathrm{CrN}$ coating as well as the Department of Surface Engineering of the IWT - Leibniz Institut für Werkstofforientierte Technologien, especially Mr. Henning 
Hasselbruch who perfomed the dilatometer tests in cooperation within the priority program SPP 1676.

\section{References}

1. K. Kellermann, C. Bareiß, S.M. Rosiwal, R.F. Singer, Advanced Engineering Materials 107 (2008) 657660

2. J. G. Buijnsters, P. Shankar, J. J. Ter Meulen, Surface and Coatings Technology 201 22-23 (2007) 89558960

3. J. G. Buijnsters, P. Shankar, W. Fleischer, W. van Enckevort, J. Schermer, J.J. ter Meulen, Diamond and Related Materials 11 3-6 (2002) 536-544

4. R. Polini, F. P. Mantini, M. Braic, M. Amar, W. Ahmed, H. Taylor, M.J. Jackson, 2006, Proceedings of the 32nd International Conference on Metallurgical Coatings and Thin Films, ICMCTF 2005, Thin Solid Films 494 1-2 (2006) 116-122

5. H. Hei, Y. Shen, J. Ma, X. Li, S. Yu, B. Tang, W. Tang, Vacuum 109 (2014) 15-20

6. O. Glozman, A. Hoffman, Diamond and Related Materials 6 (1997) 796-801

7. M. Amaral, F. Almeida, A. J. S. Fernandes, F. M. Costa, F. J. Oliveira R. F. Silva, Surf. Coat. Technol. 204 21-22 (2010) 3585-3591

8. R. K. Singh, D. R. Gilbert, J. Fitz-Gerald, S. Harkness, D.G. Lee, Science 272 (1996) 396-398

9. H. Wako, T. Abe, T. Takagi, und T. Ikohagi, Appl. Surf. Sci. 2565 (2009) 1466-1471

10. Z. Xu, L. Lev, M. Lukitsch, A. Kumar, Diamond and Related Materials 163 (2007) 461-466

11. H. Gomez, D. Durham, X. Xiao, M. Lukitsch, P. Lu, K. Chou, A. Sachdev, A. Kumar, J. Mater. Process. Technol. 2122 (2012) 523-533

12. D. G. Lee, D. R. Gilbert, S. M. Lee, R. K. Singh, Compos. Part B Eng. 307 (1999) 667-674

13. M. Prieske, Proc. of 12th Intern. Conf. The "A" coatings 2016 TEWISS-Technik und Wissen GmbH (PZH Verlag) Hannover 3 (2016) 99-106

14. R. Börner, A. Schubert, S. Winkler, T. Junge, C. Titsch, A. Schubert, W.-G. Drossel, Journal of Materials Processing Tech. 255C (2018) 749-759

15. M. Prieske, C. Wiegmann, M. Schwander, F. Vollertsen, Dry Met. Form. OAJ FMT 1 (2015) 1-4

16. A.C. Ferrari, J. Robertson, Mathematical, Physical and Engineering Sciences 362 (2004) 2477-2512

17. A.C. Ferrari, Solid State Communications 143 (2007) $47-57$

18. Q. Zhang, S.F. Yoon, J. Ahn, Rusli, Y.-P. Guo, Microelectronics Journal 29 (1998) 875-879
19. http://www.dorrenberg.es/download/aceros/DOE/1. 2379_deu.pdf, opened 19th Jan. 2018 